\title{
Open access: is there a predator at the door?
}

\author{
Dear Readers,
}

If your inbox looks like ours, you are barraged daily with requests to send research to a new journal or to join a new editorial board. Many of these 'invitations' are from new open access journals, not all of which are legitimate.

Open access journals play an increasingly important role in today's world of medical publication, and provide information which would otherwise be difficult or impossible for some to access. Openly sharing peerreviewed information at no cost to the reader can greatly enhance the distribution of legitimate scientific and clinical data. However, there is also an increasing number of journals purporting to serve this mission but acting in a predatory fashion. Here are a few guidelines.

Hallmarks of legitimate journals include:

- A well-known editorial board of recognised experts in the field;

- An International Standard Serial Number ('ISSN');

- Listing in the Directory of Open Access Journals (at https:// doaj.org);

- Publisher membership in the Open Access Scholarly Publishers Association;

- Affiliation with recognised societies;

- The journal website provides complete contact information;

- All publication fees are clearly listed and are not submission fees.

What defines a predatory journal? Moher and Moher recently summed up the characteristics neatly by suggesting that such publications can, perhaps, be characterised by their behaviour: aggressive recruitment emails, unrealistic promises regarding publication and ultimately worthless peer review. ${ }^{1}$

A number of published articles suggest the lack of an editorial review process as a key characteristic of predatory journal publications. One article described predatory journal publications as 'gobbledegook'. ${ }^{2}$ In 2005, Massachusetts Institute of Technology researchers invented software called SCIgen, which randomly combined strings of words to produce fake computergenerated science papers that were ultimately published in open access journals. This exercise was performed to show the low bar for acceptance of papers, which were meaningless, or as they put it, 'to maximize amusement'. In 2014, Van Noorden pointed out in Nature News that several publishers were removing more than 120 papers from their subscription services after it was discovered that 'the works were computer-generated non-sense'. ${ }^{3}$

More subtle forms of non-gibberish, but also non-peerreviewed publications, seem to be expanding rapidly. Rather than motivation of the publisher to promote the science and practice of medicine, the impetus is clearly financial. They charge large sums of money to publish articles unable to pass a rigorous editorial or peerreview process, which can be quite lucrative. Likewise, authors who may have been rejected by legitimate peerreviewed journals may find that some open access journals offer an avenue for publication without editorial oversight. Therefore, we suggest the following guidelines when evaluating whether a journal is predatory.

Be cautious if:

- Invitations to submit research or to join editorial boards are overly flattering;

- There is a guarantee of rapid publication;

- The journal title is very similar to that of a legitimate journal, but is not an established journal;

- The journal website has no address or contact information;

- The mission of the publisher and/or the journal is described in vague terms;

- There is no mention of peer review or basic submission requirements;

- Manuscripts are submitted by email rather than through the publisher's online manuscript peerreview system;

- There is a requirement to submit a minimum number of articles per year, and there is no clear statement that your open access publication fee will be waived.

We recommend an excellent recent editorial by Roberts, which shares our opinion, entitled 'Predatory journals: think before you submit' ${ }^{4}$

Our goal is to provide high-quality, rigorously peerreviewed papers and scientific information of value to you and all of our readers.

RAKESH CHANDRA, Co-Editor-in-Chief, American Journal of Rhinology \& Allergy

EDWARD W FISHER, Senior Editor, The Journal of Laryngology \& Otology

TERRY M JONES, Editor-in-Chief, Clinical Otolaryngology 
DAVID W KENNEDY, Editor-in-Chief, International Forum of Allergy \& Rhinology

DENNIS H KRAUS, Co-Editor-in-Chief, Journal of Neurological Surgery Part B

JOHN H KROUSE, Editor-in-Chief, Otolaryngology Head \& Neck Surgery; Editor-in-Chief, OTO Open

MICHAEL LINK, Co-Editor-in-Chief, Journal of Neurological Surgery Part B

LAWRENCE R LUSTIG, Editor-in-Chief, Otology \& Neurotology

BERT W O'MALLEY JR, Editor-in-Chief, Journal for Oto-Rhino-Laryngology, Head and Neck Surgery

JAY F PICCIRILLO, Editor-in-Chief, JAMA Otolaryngology - Head \& Neck Surgery

ROBERT RUBEN, Editor-in-Chief, International Journal of Pediatric Otorhinolaryngology

ROBERT T SATALOFF, Editor-in-Chief, Journal of Voice; Editor-in-Chief, Ear, Nose \& Throat Journal SANDRA SCHWARTZ, ORL - Head and Neck Nursing
RAJ SINDWANI, Co-Editor-in-Chief, American Journal of Rhinology \& Allergy

RICHARD J SMITH, Editor-in-Chief, The Annals of Otology, Rhinology \& Laryngology

MICHAEL G STEWART, Editor-in-Chief, The Laryngoscope

PETER C WEBER, Editor-in-Chief, American Journal of Otolaryngology

D BRADLEY WELLING, Editor-in-Chief, Laryngoscope Investigative Otolaryngology

ROBIN YOUNGS, Senior Editor, The Journal of Laryngology \& Otology

References

1 Moher D, Moher E. Stop predatory publishers now: act collaboratively. Ann Intern Med 2016;164:616-17

2 Ball P. Computer conference welcomes gobbledegook paper. Nature 2005;434:946

3 Van Noorden R. Publishers withdraw more than 120 gibberish papers. Nature News 24 Feb 2014

4 Roberts J. Predatory journals: think before you submit. Headache 2016;56:618-21 